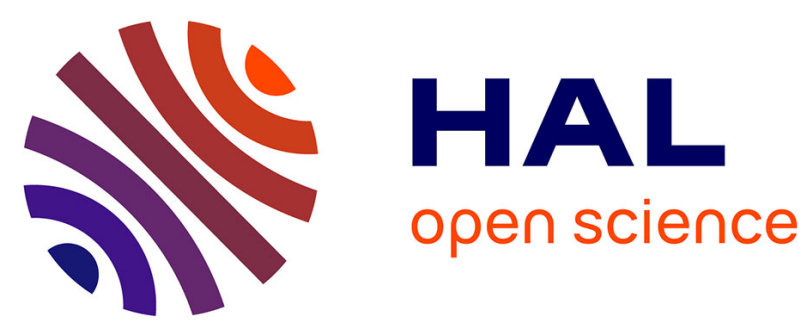

\title{
Strength effects in micropillars of a dispersion strengthened superalloy
}

Baptiste Girault, Andreas Schneider, Carl Frick, Eduard Arzt

\section{To cite this version:}

Baptiste Girault, Andreas Schneider, Carl Frick, Eduard Arzt. Strength effects in micropillars of a dispersion strengthened superalloy. Advanced Engineering Materials, 2010, 12 (5), pp.385-388. 10.1002/adem.201000089 . hal-01007328

\section{HAL Id: hal-01007328 \\ https://hal.science/hal-01007328}

Submitted on 8 Mar 2017

HAL is a multi-disciplinary open access archive for the deposit and dissemination of scientific research documents, whether they are published or not. The documents may come from teaching and research institutions in France or abroad, or from public or private research centers.
L'archive ouverte pluridisciplinaire HAL, est destinée au dépôt et à la diffusion de documents scientifiques de niveau recherche, publiés ou non, émanant des établissements d'enseignement et de recherche français ou étrangers, des laboratoires publics ou privés. 


\title{
Strength Effects in Micropillars of a Dispersion Strengthened Superalloy**
}

\author{
By Baptiste Girault*, Andreas S. Schneider, Carl P. Frick and Eduard Arzt
}

The present paper investigates the uniaxial compression behavior of highly alloyed, focused ion beam (FIB) manufactured micropillars, ranging from $200 \mathrm{up}$ to $4000 \mathrm{~nm}$ in diameter. The material used was the Ni-based oxide-dispersion strengthened (ODS) alloy Inconel MA6000. Stress-strain curves show a change in slip behavior comparable to those observed in pure fcc metals. Contrary to pure Ni pillar experiments, high critical resolved shear stress (CRSS) values were found independent of pillar diameter. This suggests that the deformation behavior is primarily controlled by the internal obstacle spacing, overwhelming any pillar-size-dependent mechanisms such as dislocation source action or starvation.

In order to realize the full potential of emerging microand nanotechnologies, investigations have been carried out to understand the mechanical behavior of materials as their internal microstructural constraints or their external size is reduced to sub-micron dimensions. ${ }^{[1,2]}$ Focused ion beam (FIB) manufactured pillar compression techniques have been used to investigate size-dependent mechanical properties at this scale on a variety of samples, including single-crystalline, ${ }^{[3-10]}$ nanocrystalline, ${ }^{[11]}$ precipitatestrengthened, ${ }^{[12,13]}$ and nanoporous ${ }^{[14,15]}$ metals. Tests revealed that single-crystal metals exhibit strong size effects in plastic deformation, suggesting that the mechanical strength of the metal is related to the smallest dimension of the tested sample. Among the various explanations that have

[*] Dr. B. Girault, Dr. A. S. Schneider, Prof. E. Arzt INM - Leibniz Institute for New Materials, Functional Surfaces Group, and Saarland University

Campus D2 2, 66123 Saarbruecken, Germany

E-mail: baptiste.girault@inm-gmbh.de

Dr. A. S. Schneider

Max Planck Institute for Metals Research Heisenbergstr. 3, 70569 Stuttgart, Germany

Dr. C. P. Frick

Department of Mechanical Engineering, University of Wyoming Department 32951000 E. University Ave., Laramie, WY 82071, USA

[**] The authors would like to acknowledge J. Schmauch, Saarland University for EBSD measurements, discussions with K.-P. Schmitt, INM, and the assistance of Christof Schwenk, Max Planck Institute for Metals Research, Stuttgart, and Birgit Heiland, INM for SEM sample surface preparation. been pointed out to account for such a mechanical behavior, one prevailing theory developed by Greer and Nix ${ }^{[6]}$ invokes "dislocation starvation." It assumes that dislocations leave the pillar via the surface before dislocation multiplication occurs. To accommodate the induced deformation new dislocations have to be nucleated, which requires high stresses. ${ }^{[6,16]}$ This theory has been partially substantiated by direct in situ transmission electron microscope (TEM) observations of FIB manufactured pillars which demonstrate a clear decrease in mobile dislocations with increasing deformation, a result ascribed to a progressive exhaustion of dislocation sources. ${ }^{[17]}$ Another origin of size-dependent strengthening may lie in the constraints on active dislocation sources exerted by the external surface, i.e., source-controlled mechanisms. ${ }^{[18-20]} \mathrm{A}$ clear understanding of the mechanisms responsible for the size effects in plastic deformation is still missing and other origins of strength modification with size remains somewhat controversial. ${ }^{[17]}$

Unlike pure metals, pillars with an internal size parameter smaller than the pillar diameter would be expected to exhibit no size effect, reflecting the behavior of bulk material. This was demonstrated for nanocrystalline ${ }^{[11]}$ and nanoporous Au. ${ }^{[14,15]}$ Nickel-titanium pillars with semi-coherent precipitates approximately $10 \mathrm{~nm}$ in size and spacing also exhibited no size dependence, although results are difficult to interpret due to the concurrent martensitic phase transformation. ${ }^{[13]}$ Conversely, precipitate strengthened superalloy pillars were reported to show size-dependent behavior, a result left largely unexplained. ${ }^{[12,21]}$ Therefore, a strong need exists to further explore the influence of internal size parameters on the mechanical properties of small-scale single crystals, to better understand the associated mechanisms responsible for the size effect. 

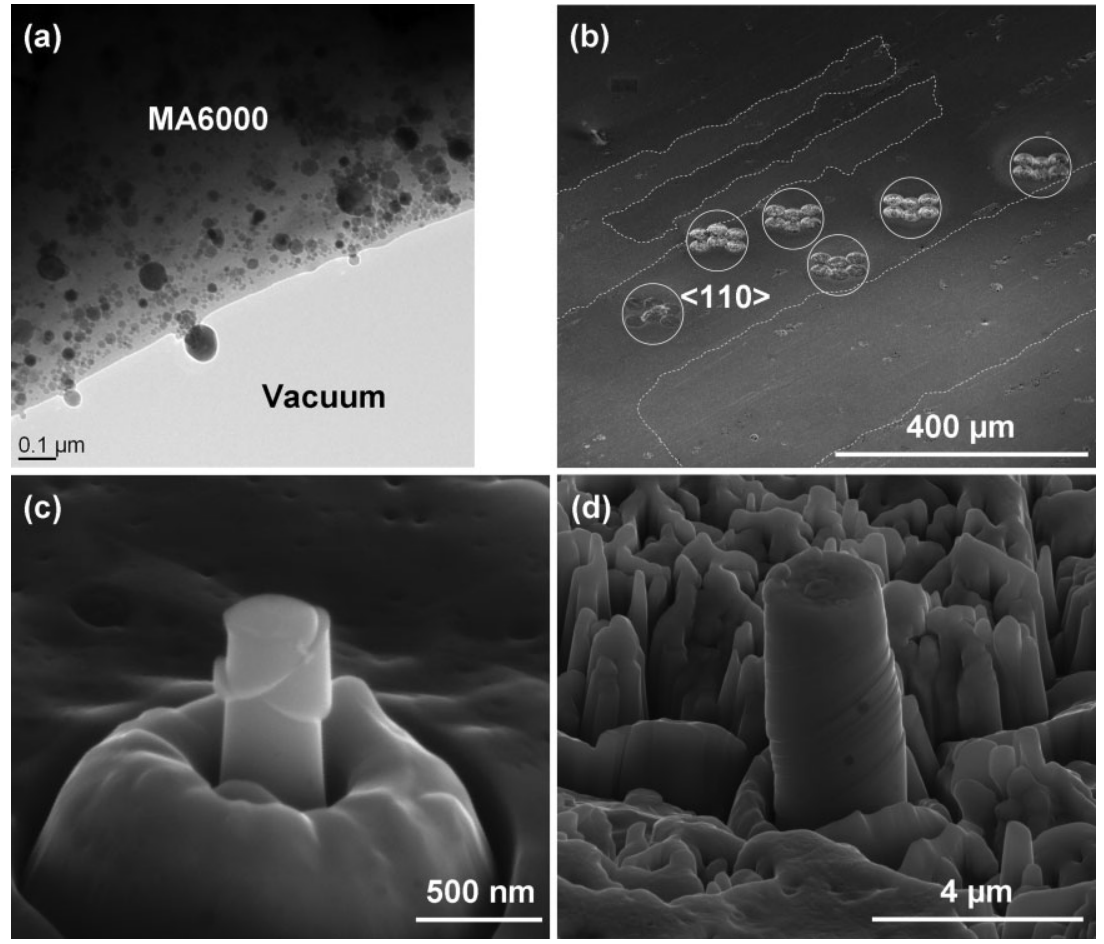

Fig. 1. TEM plane view of MA6000 microstructure (a) and SEM images of (b) location of pillar series (white circles) with regards to grains boundaries (white dotted lines); (c) and (d) show deformed pillars with diameter of 304 and $1970 \mathrm{~nm}$, respectively. Pictures were taken at a $52^{\circ}$ tilt angle relative to the surface normal.

The research presented here investigates the mechanical behavior of single-crystalline micropillars made of a dispersion strengthened metal with a small internal size scale: the oxide-dispersion strengthened (ODS) Inconel MA6000, ${ }^{1}$ which is a highly strengthened Ni-based superalloy produced by means of mechanical alloying. This high-energy ball milling process produces a uniform dispersion of refractory particles $\left(\mathrm{Y}_{2} \mathrm{O}_{3}\right)$ in a complex alloy matrix, and is followed by thermo-mechanical and heat treatments (hot-extrusion and hot-rolling) to obtain a large grained microstructure (in the millimeter range). MA6000 has a nominal composition of Ni-15Cr-4.5A1-2.5Ti-2Mo-4W-2Ta-0.15Zr-0.01B-0.05C-1.1 $\mathrm{Y}_{2} \mathrm{O}_{3}$, in $w t \%$. Previous studies carried out on bulk MA6000 showed that its strength is due to the oxide dispersoids and to coherent precipitates of globular-shaped $\gamma^{\prime}-\left(\mathrm{Ni}_{3} \mathrm{Al} / \mathrm{Ti}\right)$ particles, which are formed during the heat treatment. Depending on the studies, the average sizes in these two-particle populations are about 20-30 and 275-300 nm, respectively. ${ }^{[22-25]}$

TEM investigations of our sample revealed a dense distribution of oxide particles with diameter and spacing well below $100 \mathrm{~nm}$; however, no indications of $\gamma^{\prime}$-precipitates were found (Fig. 1(a)). Thus, in contrast to a recent study on nanocrystalline pillars, ${ }^{[11]}$ the tested specimens have no internal grain boundaries, which would impede the dislocations from leaving the sample, but have a characteristic length scale smaller than the pillar diameter.

${ }^{1}$ Inconel MA6000 is a trademark of the Inco Alloys International, Inc., Huntington, WV.

\section{Experimental}

Bulk MA6000 was mechanically and chemically polished. The polishing process and testing were carried out in a plane allowing access to elongated grains of several millimeters in size. Pillar manufacturing, testing, and analysis were similar to the study by Frick et al. ${ }^{[26]}$. Micro- and nanopillars with diameters ranging from 200 to $4000 \mathrm{~nm}$ and a diameter to length aspect ratio of approximately 3:1 were machined with a FIB FEI Nova 600 NanoLab DualBeam ${ }^{\mathrm{TM}}$. All pillars were FIB manufactured within the same grain (Fig. 1(b)) in order to avoid any crystallographic orientation changes that could activate different slip systems. To minimize any FIB-related damage, a decreasing ionic current intensity from $0.3 \mathrm{nA}$ down to $10 \mathrm{pA}$ was used as appropriate with decreasing pillar diameters ${ }^{[27]}$. The pillars were subsequently compressed in loadcontrol mode by an MTS XP nanoindenter system equipped with a conical diamond indenter with a flat $10 \mu \mathrm{m}$ diameter tip under ambient conditions. Loading rates varied between 1 and $250 \mu \mathrm{N} \cdot \mathrm{s}^{-1}$ depending on pillar diameter in order to obtain equal stress rates of $20 \mathrm{MPa} \cdot \mathrm{s}^{-1}$.

The pillar diameter, measured at the top of the column, was used to calculate the engineering stress. It is important to mention that the pillars had a slight taper of approximately $2.7^{\circ}$ on average, with a standard deviation of $0.5^{\circ}$. Hence, stress as defined in this study represents an upper bound to the stress experienced by the sample during testing.

Figure 1(c) and (d) shows representative post-compression scanning electron microscope (SEM) micrographs of 304 and $1970 \mathrm{~nm}$ diameter pillars. Pillars with diameters above $1000 \mathrm{~nm}$ retained their cylindrical shape and showed multiple slip steps along their length; in some cases, barreling was observed. Samples below this approximate size tended to show localized deformation at the top with fewer, concentrated slip steps, which have been observed in previous studies, e.g., see Ref. [28]. Independent of pillar size, multiple slip was observed. High-magnification pictures of the sidewalls showed fewer slip steps in the vicinity of particles, emphasizing that particles act as efficient dislocation obstacles.

Electron backscattered diffraction (EBSD) measurements showed that the pillars were cut in a grain with the $\langle 110\rangle$ crystallographic orientation aligned normal to the sample surface. Among the 12 different possible slip systems in fcc crystals, only four present a non-zero Schmid factor equal to 0.41 . The slip bands were oriented at approximately $34^{\circ}$ with regard to the pillar axis, nearly matching the expected $35.3^{\circ}$ angle of the $\{111\}\langle 110\rangle$ slip system for a $\langle 110\rangle$ oriented fcc crystal. 


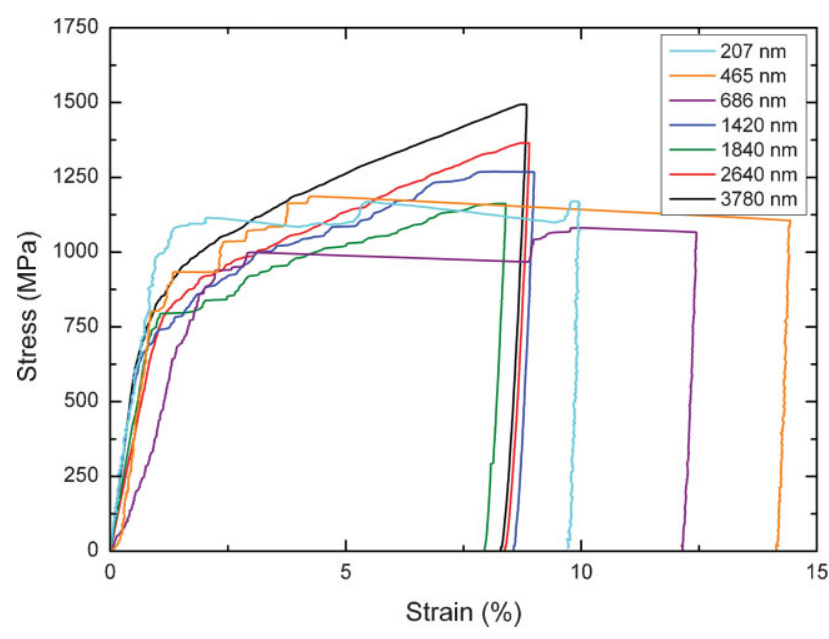

Fig. 2. Representative compressive stress-strain behavior for MA6000 pillars of various diameters ranging from approximately 200 to $4000 \mathrm{~nm}$.

\section{Results and Discussion}

Typical engineering stress-strain curves are shown in Figure 2. The features of the stress-strain curves changed with decreasing pillar diameter. Larger pillars displayed a stressstrain curve with strain hardening similar to bulk material. Below approximately $2000 \mathrm{~nm}$, staircase-like stress-strain curves with plastic strain bursts separated by elastic loading segments were observed. This has been demonstrated in previous single-crystalline micropillar studies, where strain bursts were related to dislocation avalanches. ${ }^{[10,26]}$ For pillars even smaller than $1000 \mathrm{~nm}$ in diameter, the staircase-like shape under $4 \%$ strain is followed by large bursts over several percent strain, which gave the appearance of strain softening. The large bursts are consistent with SEM observations showing highly localized deformation on a few glide planes for pillars with diameters below $1000 \mathrm{~nm}$. This behavior suggests that, for small pillar diameters, the dispersoid particles no longer promote homogeneous deformation, as they do in bulk alloys. The pillars hence exhibit a size effect in the slip behavior.

By contrast, the flow stresses are comparable for all pillar diameters and do not exhibit a size effect (Fig. 2). This is highlighted in Figure 3, where the flow stress measured at 3\% strain is plotted as a function of pillar diameter, and compared with previous results on pure Ni micropillar. ${ }^{[4,26]}$ Whereas the pure Ni exhibits the frequently reported size effect, our data are independent of pillar diameter and lie close to the bulk value (critical resolved shear stress (CRSS) of about 500 $\mathrm{MPa}^{[23]}$. Best power-law fits gave a relationship between flow stress $\sigma$ and diameter $d$ of $\sigma \alpha d^{-0.65}$ and $d^{-0.62}$ for [111] and [269] $\mathrm{Ni}$, respectively; for MA6000, the exponent is $-0.04 \pm 0.02$, a value close to zero.

In contrast to the study on a superalloy containing only coherent precipitates, ${ }^{[12]}$ this study clearly shows that incoherent particles can give rise to an internal size parameter, which is dominant over any pillar-size effect in the entire size

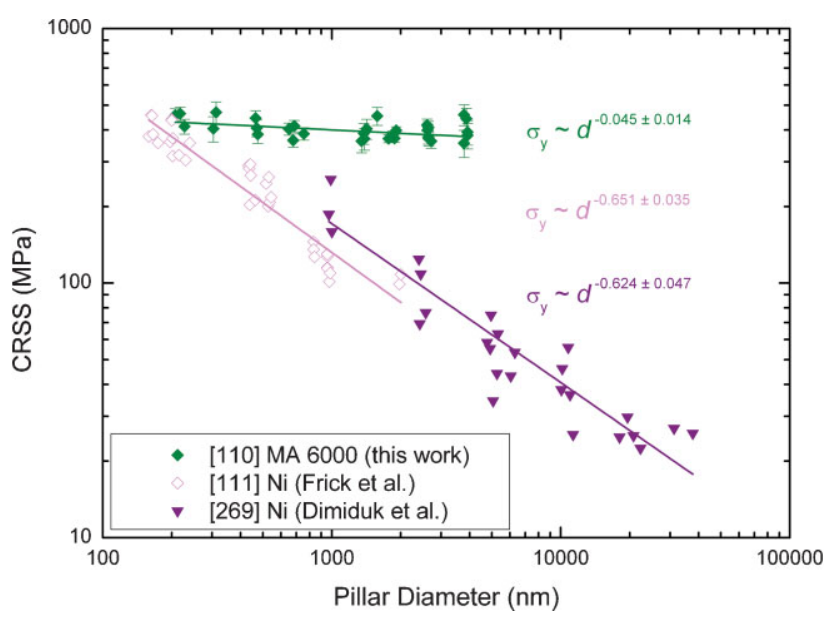

Fig. 3. Logarithmic plot of the critical resolved shear stress (CRSS) at 3\% strain for all [111] MA6000 pillars tested. The error bars correspond to the standard deviation of six tests on different pillars presenting similar diameters. For comparison, $0.2 \%$ offset compressive stresses are shown for pure [269] $\mathrm{Ni}^{[5]}$ and 3\% offset values for [111] $\mathrm{Ni}^{[23]}$ The solid lines represent best power-law fits.

range. The oxide particle spacing in our study is below $100 \mathrm{~nm}$, which is much smaller than the pillar diameters. ${ }^{[22-25]}$ It is notable that the extrapolated MA6000 strength values and the pure Ni data in Figure 3 intersect at a pillar diameter of about $150 \mathrm{~nm}$, close to the oxide particle spacing. The smallest pillars still contain about 10, the largest about 40000 oxide particles. In the latter case, continuous stress-strain curves as in bulk are expected due to averaging effects; in the smaller pillars, stochastic effects would explain the staircase-like behavior.

The absence of the size effect in single-crystalline MA6000 implies that neither the starvation theory nor sourcecontrolled mechanisms may be applicable. The high density of internal obstacles will be likely to prevent dislocations from exiting excessively through the surface; and the small obstacle spacing, compared to the pillar diameter, will make source-operation insensitive to surface effects. As a result, the flow stress will be determined by the interactions of dislocations and obstacles, as in bulk alloys. Size effects might, however, be expected for pillar diameters below the oxide particle spacing, i.e., $100 \mathrm{~nm}$, but are beyond the scope of the present study.

\section{Conclusions}

In summary, compression tests were carried out on single-crystal pillars of an ODS-Ni superalloy (MA6000). The following conclusions were drawn:

i) As in pure fcc metals, the superalloy pillars undergo a change in slip behavior. Pillars thinner than $2000 \mathrm{~nm}$ showed staircase-like stress-strain curves. The localized strain bursts suggest that the non-shearable particles no longer manage to homogenize slip as in bulk alloys.

ii) Contrary to single-crystal studies on pure metals, no dependence of yield stress on sample size was measured. A high constant strength was found, which is comparable 
to the highest flow stress value published for pure $\mathrm{Ni}$ pillars (with a diameter of $150 \mathrm{~nm}$ ).

iii) These results suggest that size-dependent mechanisms such as dislocation starvation or source exhaustion are not operative in a dispersion strengthened alloy. Instead, the strong internal hardening dominates over any specimen size effect.

[1] E. Arzt, Acta Mater. 1998, 46, 5611.

[2] T. Volpp, E. Göhring, W.-M. Kuschke, E. Arzt, Nanostruct. Mater. 1998, 7, 855.

[3] M. D. Uchic, D. M. Dimiduk, J. N. Florando, W. D. Nix, Science 2004, 305, 986.

[4] D. M. Dimiduk, M. D. Uchic, T. A. Parthasarathy, Acta Mater. 2005, 53, 4065.

[5] M. D. Uchic, D. M. Dimiduk, R. Wheeler, P. A. Shade, H. L. Fraser, Scr. Mater. 2006, 54, 759.

[6] J. R. Greer, W. D. Nix, Phys. Rev. B. 2006, 73, 245410.

[7] C. A. Volkert, E. T. Lilleodden, Philos. Mag. 2006, 86, 5567.

[8] D. Kiener, C. Motz, T. Schöberl, M. Jenko, G. Dehm, Adv. Eng. Mater. 2006, 8, 1119.

[9] W. D. Nix, J. R. Greer, G. Feng, E. T. Lilleodden, Thin Solid Films 2007, 515, 3152.

[10] R. Maaß, S. Van Petegem, H. Van Swygenhoven, P. M. Derlet, C. A. Volkert, D. Grolimund, Phys. Rev. Lett. 2007, 99, 145505.

[11] B. E. Schuster, Q. Wei, H. Zhang, K. T. Ramesh, Appl. Phys. Lett. 2006, 88, 103112.

[12] D. M. Dimiduk, M. D. Uchic, S. I. Rao, C. Woodward, T. A. Parthasarathy, Modell. Simul. Mater. Sci. Eng. 2007, 15, 135.

[13] C. P. Frick, S. Orso, E. Arzt, Acta Mater. 2007, 55, 3845.
[14] J. Biener, A. M. Hodge, J. R. Hayes, C. A. Volkert, L. A. Zepeda-Ruiz, A. V. Hamza, F. F. Abraham, Nano Lett. 2006, 6, 2379.

[15] C. A. Volkert, E. T. Lilleodden, D. Kramer, J. Weissmuller, Appl. Phys. Lett. 2006, 89, 061920.

[16] J. R. Greer, W. C. Oliver, W. D. Nix, Acta Mater. 2005, 53, 1821.

[17] Z. W. Shan, R. K. Mishra, S. A. Syed Asif, O. L. Warren, A. M. Minor, Nat. Mater. 2008, 7, 115.

[18] B. von Blanckenhagen, P. Gumbsch, E. Arzt, Modell. Simul. Mater. Sci. Eng. 2001, 9, 157.

[19] B. von Blanckenhagen, P. Gumbsch, E. Arzt, Philos. Mag. Lett. 2003, 83, 1.

[20] B. von Blanckenhagen, E. Arzt, P. Gumbsch, Acta Mater. 2004, 52, 773.

[21] M. D. Uchic, D. M. Dimiduk, Mater. Sci. Eng. A 2005, 400, 268.

[22] J. H. Schröder, E. Arzt, Scr. Metall. 1985, 19, 1129.

[23] R. F. Singer, E. Arzt, in High Temperature Alloys for Gas Turbines and Other Applications (Eds: W. Betz, R. Brunetaud, D. Coutsouradis, H. Fischmeister, I. Kvernes, Y. Lindblom, J. B. Marriott, D. B. Meadowcroft), D. Reidel Publishing Company, 1986, p. 97.

[24] B. Reppich, W. Listl, T. Meyer, in High Temperature Alloys for Gas Turbines and Other Applications (Eds: W. Betz, R. Brunetaud, D. Coutsouradis, H. Fischmeister, I. Kvernes, Y. Lindblom, J. B. Marriott, D. B. Meadowcroft), D. Reidel Publishing Company, 1986, p. 1023.

[25] M. Heilmaier, B. Reppich, Metall. Mater. Trans. A 1996, 27, 3862.

[26] C. P. Frick, B. G. Clark, S. Orso, A. S. Schneider, E. Arzt, Mater. Sci. Eng. A 2008, 489, 319.

[27] S. Shim, H. Bei, M. K. Miller, G. M. Pharr, E. P. George, Acta Mater. 2009, 57, 503.

[28] Z. W. Shan, R. K. Mishra, S. A. S. Asif, O. L. Warren, A. M. Minor, Nat. Mater. 2008, 7, 115. 